\title{
Prevalence and associated factors of low birth weight in Axum town, Tigray, North Ethiopia
}

\author{
Wondim Aboye ${ }^{1}$, Tesfay Berhe ${ }^{1}$, Taddis Birhane ${ }^{1}$ and Hadgu Gerensea ${ }^{2^{*}}$
}

\begin{abstract}
Objective: Weight at birth is a good indicator of the newborn's chances for survival, growth, long-term health and psychosocial development. Therefore, the aimed of this study is to assess the prevalence and associated factors of low birth weight in Axum town, Tigray, North Ethiopia.

Result: The magnitude of low birth weight was $8.8 \%$. Height of mother adjusted odds ratio (AOR) 4.607 (Cl 1.3415.8), gestational age AOR 4.7 (Cl 1.08-20.44), anti-natal care (ANC) visit AOR 0.076 (Cl 0.009-0.645), anemia during pregnancy AOR 14.5 (Cl 3.821-55.6) and drinking alcohol AOR 6.4 (Cl 1.235-33.94) were found to be significantly associated with low birth weight. Pre-conceptual counseling on nutrition, about the effect of short suture on birth outcome and personal maternal habit (drinking alcohol), effective treatment and prevention of anemia and awareness on the importance ANC follow up should be the target.
\end{abstract}

Keywords: LBW, Aksum, Ethiopia

\section{Introduction}

Low birth weight (LBW) is defined by the World Health Organization as weight at birth $<2500 \mathrm{~g}(5.5 \mathrm{lb})$. There is significant fluctuation in the number of low birth weight across regions and within state; however, the great figure of low birth weight births happen in low- and middleincome countries and particularly in the most vulnerable populations [1].

Based on national and regional estimates in Ethiopia $2,600,000$ live births are reported out of these live births 530,400 infants are LBW with mortality rate of $32.4 \%$. In Ethiopia the low birth weight (LBW) estimate has risen from 2000 to 2005 from 15.0 to $20.3 \%$ with $1.1 \%$ increase per year [2]. In Ethiopia, having one of the highest neonatal mortality rate in the world, recent estimates shows that the median prevalence of low birth weight is around $11 \%$ and ranges high up as $23 \%$. Mother's height, mother's weight, anemia, physical work, tobacco chewing, and

\footnotetext{
*Correspondence: hadguellen1@gmail.com

${ }^{2}$ School of Nursing, College of Health Science, Aksum University, Aksum, Ethiopia

Full list of author information is available at the end of the article
}

history of abortion are significant determinants of LBW [3].

This study will seek to ascertain the prevalence of low birth weight, describe the socio-demographic characteristics of women attending delivery and to investigate the factors contributing to LBW in Aksum town. The findings will create awareness in the community about the problem and contribute towards formulating locally appropriate interventions to prevent low birth weight. The findings will be shared among various stakeholders to stimulate focused intervention programs.

\section{Main text \\ Methodology \\ Study area and design}

Institutional based cross-sectional study was conducted in St. Marry hospital and Aksum University specialized and comprehensive hospital, Aksum, Tigray region regional state, Ethiopia, Which is the capital town of central zone of Tigray regional state. Aksum is found at a distance of $1024 \mathrm{~km}$ from Addis Ababa, capital city of Ethiopia and $241 \mathrm{~km}$ north of Mekelle, the capital city of Tigray [4-14]. 


\section{Study period}

The study was conducted from April1/2018 to May30/2018.

\section{Source population and study population}

All mothers who give birth at Aksum St. Marry hospital and Aksum university comprehensive specialized hospital, central zone of Tigray and those who randomly selected mothers were the study participant.

\section{Sample size determination}

A total 308 samples were calculated using the formula to estimate a single Population proportion.

With the assumption of $95 \%$ confidence interval (CI), $\mathrm{d}=0.035$ and prevalence of LBW of the new born in Aksum town research shows 9.9\%.

\section{Sampling procedure and technique}

The calculated sample size (308) was proportionally allocated to these health facilities based on delivery case load of each health facility. Finally, data was collected systematically by skipping every third neonate until the needed sample size was found.

\section{Data collection procedures}

The data was collected using structured, pretested interviewer administered questionnaire containing socio-demographic characteristics and other variables associated with delivering LBW baby. Data was collected through interviewing the mother and measuring the weight of the newborn, height, weight and mid-upper arm circumference (MUAC) of the mother (see Additional file 1).

\section{Dependent variable Low birth weight.}

\section{Independent variable}

- Demographic and socio-economics: characteristics, including newborn sex, maternal age, family monthly income, educational level, maternal occupation, religion, marital status ethnicity.

- Maternal anthropometry (nutritional status): prepregnancy weight, maternal MUAC, maternal height, maternal weight.

- Obstetric and gynecologic factor: parity, birth interval, history of abortion, anemia, chronic illness of the mother, gestational age at birth, no of anti-natal care (ANC) follows up.
- Maternal behavior: khat, alcohol, physical activity.

\section{Data management, processing and analysis}

The data was entered to Statistical Package for Social Sciences (SPSS) version 21.0. Identification of implausible values and missing data or possibly miss-coded data was cross-checked. After cleaning the data, frequencies and percentages was calculated to all variables. Bivariate analysis; cross tabulations was done to see the association between the explanatory and outcome variables. Multivariable logistic regression was employed by selecting only variables that appeared to be statistically significant at $(\mathrm{P}<0.05)$ in the bivariate analysis. Model fit was checked by Hosmer-Lemeshow goodness-of-fit test.

Finally, the data was presented with appropriate tables, diagrams and figures. Adjusted odd ratio (AOR) was calculated to check strength of association and $\mathrm{P}<0.05$ was taken as significant association.

\section{Results}

\section{Socio demographic characteristics of the respondents}

Majority of mothers 208 (67.5\%) were aged 20-34. All of the mothers were Tigrean in ethnic. Majority of the mothers were married 286 (92.9). Out of the respondent 298 (96.1\%) were Orthodox Christians. Majority of the respondent 157 (51\%) of mothers could not read and write and 133 (43.3\%) of mothers were housewife. More than half of mothers 188 (61\%) respondents were residing in urban areas. Based on the findings from the income distribution higher percentage of mothers 95 (30\%) had an average household income of $<1000$ ETB per month (Table 1).

\section{Bivariable and multivariable logistic regression analysis of factors associated with LBW}

In bivariate analysis, religion, residence, height of mother, weight of mother, gestational age, ANC visit, anemia during pregnancy, drinking alcohol and frequency of alcohol drinking were found to be associated with low birth weight.

But, in multivariate analysis, only height of mother AOR 4.607 (CI 1.34-15.8), gestational age AOR 4.7 (CI 1.08-20.44), ANC visit AOR 0.076 (CI 0.009-0.645), anemia during pregnancy AOR 14.5 (CI 3.821-55.6) and drinking alcohol AOR 6.4 (CI 1.235-33.94) were found to be significantly associated with low birth weight.

Mothers whose height $<150 \mathrm{~cm}$ was 4.6 times more likely to deliver low birth weight baby than mothers with height of $\geq 150 \mathrm{~cm}$ (AOR 4.607 (CI 1.34-15.8)). The chance of LBW delivery were 4.7 times higher for neonate with gestational age < 37 weeks 4.7 (CI 1.08-20.44). Mother who had ANC follow up had $92.4 \%$ less chance to 
Table 1 Distribution of mothers by socio demographic characteristics in Axum St. Marries hospital and Aksum university comprehensive specialized hospital, Tigray, Northern Ethiopia, 2018

\begin{tabular}{|c|c|c|c|}
\hline Variables & Categories & Frequency & Percentage (\%) \\
\hline \multirow[t]{3}{*}{ Age of mothers (years) } & $<20$ & 80 & 26 \\
\hline & $20-34$ & 208 & 67.5 \\
\hline & $\geq 35$ & 20 & 6.5 \\
\hline \multirow[t]{3}{*}{ Religion } & Orthodox Christian & 296 & 96.1 \\
\hline & Muslim & 9 & 2.9 \\
\hline & Others & 3 & 1.0 \\
\hline \multirow[t]{5}{*}{ Educational status } & Unable to read and write & 157 & 51 \\
\hline & Able to read and write & 17 & 5.5 \\
\hline & Primary school (1-8) & 34 & 11 \\
\hline & Secondary school (9-12) & 61 & 19.8 \\
\hline & College and above & 38 & 12.3 \\
\hline \multirow[t]{5}{*}{ Marital status } & Single & 5 & 1.6 \\
\hline & Married & 286 & 92.9 \\
\hline & Divorced & 3 & 1.0 \\
\hline & Separated & 9 & 2.6 \\
\hline & Widowed & 5 & 1.6 \\
\hline \multirow[t]{5}{*}{ Occupation } & Employed & 67 & 21.8 \\
\hline & Housewife & 133 & 43.2 \\
\hline & Farmer & 91 & 29.5 \\
\hline & Merchants & 14 & 4.5 \\
\hline & Daily laborer & 3 & 1 \\
\hline \multirow[t]{4}{*}{ Monthly income (Birr) } & $<500$ & 52 & 16.9 \\
\hline & $500-1000$ & 95 & 30.8 \\
\hline & $>1000-2000$ & 78 & 25.3 \\
\hline & $>2000$ & 83 & 26.9 \\
\hline \multirow[t]{2}{*}{ Residence } & Urban & 188 & 61 \\
\hline & Rural & 120 & 39 \\
\hline
\end{tabular}

have low birth weight baby AOR 0.076 (CI 0.009-0.645) than those who didn't have. Mothers who had anemia during current pregnancy were 14 times more likely to deliver low birth weight neonate compared to mothers without anemia AOR: AOR 14.5 (CI 3.821-55.6). Mothers who drink alcohol during current pregnancy were 6.4 times more likely to deliver low birth weight neonate compared to mothers who didn't drink AOR 6.4 (CI 1.235-33.94). Further see Table 2.

\section{Discussion}

Low birth weight observed in this study was consistent with studies conducted in Iran (8.8\%), Jimma (11.02\%), [15] Nigeria (7.3\%), [16], Laelay Maichew (6.6\%) and Axum district (9.9\%) [17]. LBW EDHS report of Ethiopia in 2011 shows $11 \%$. The possible explanation between the variations might be the difference in geographical variation which might had difference in health service utilization and nutritional status of mothers during pregnancy.
But it had relatively lower when compared with study finding done in India, Uttar Pradesh which was about $40 \%$ [18] and study conducted in Kersa demographic and Surveillance and Health research Center (KDS-HRC) which showed an incidence of $28.3 \%$ [19]. The possible explanation for the decrement in LBW in the current study might be the study done in Kersa was done in rural area. The other explanation might be due to variation in characteristics of study population like nutritional status and maternal feeding habit.

In this study, anemia during pregnancy, height of the mother $<150 \mathrm{~cm}$, gestational age at birth $<37$ weeks, number of ANC visit and drinking alcohol were found to be significantly associated with low birth weight.

Mothers who had anemia during current pregnancy were 14 times more likely to deliver low birth weight neonate compared to mothers without anemia (AOR: 14.5 (CI 3.821-55.6). This finding consistent with study conducted in Deberbirhan Ethiopia and Sudan [20, 21]. Anemia also found to increase chance of LBW in which the 
Table 2 Bivariable and multivariable logistic regression analysis of factors associated with LBW in Axum St. Marry Hospital and Aksum university comprehensive specialized hospital northern Ethiopia, 2018

\begin{tabular}{|c|c|c|c|c|c|c|c|}
\hline \multirow[t]{3}{*}{ Variables } & \multirow[t]{3}{*}{ Characteristics } & \multicolumn{2}{|l|}{ Birth weight } & \multirow[t]{3}{*}{ COR } & \multirow[t]{3}{*}{ P-value } & \multirow[t]{3}{*}{ AOR } & \multirow[t]{3}{*}{$P$ value } \\
\hline & & NBW & LBW & & & & \\
\hline & & FR (\%) & FR (\%) & & & & \\
\hline \multirow[t]{2}{*}{ Religion } & Orthodox & $271(91.6 \%)$ & $25(8.4 \%)$ & $21.7046(0.004-0.527)$ & 0.013 & 0.195 (0.009-4.092) & 0.293 \\
\hline & Others & $10(83.3 \%)$ & $2(16.7 \%)$ & $2.000(-)$ & 1 & $0.000(000-0.0001)$ & 1 \\
\hline \multirow[t]{2}{*}{ Residence } & Urban & $177(94.1 \%)$ & $11(5.9 \%)$ & $0.4(0.181-0.903)$ & 0.027 & $1.100(0.333-3.636)$ & 0.876 \\
\hline & Rural & $104(86.7 \%)$ & $16(13.3 \%)$ & $0.154(-)$ & 1 & - & - \\
\hline \multirow[t]{2}{*}{ Height of mother $(\mathrm{cm})$} & $<150$ & $34(68 \%)$ & $16(32 \%)$ & $10.5(4.529-24.655)$ & 0.00 & $4.607(1.34-15.8)^{*}$ & 0.015 \\
\hline & $\geq 150$ & 247 (95.7\%) & $11(4.3 \%)$ & $0.045(-)$ & 1 & - & 1 \\
\hline \multirow[t]{2}{*}{ Weight of mother (kg) } & $<50$ & $97(86.6 \%)$ & $15(13.4 \%)$ & $2.37(1.068-5.266)$ & 0.034 & $0.614(0.173-2.187)$ & 0.452 \\
\hline & $\geq 50$ & $184(93.9 \%)$ & $12(6.1 \%)$ & $0.065(-)$ & 1 & - & 1 \\
\hline \multirow[t]{2}{*}{ GA (weeks) } & $<37$ & $17(63 \%)$ & $10(37 \%)$ & 9.135 (3.632-22.975) & 0.0 & $4.7(1.08-20.44)^{*}$ & 0.038 \\
\hline & $\geq 37$ & 264 (94\%) & $17(6 \%)$ & $0.064(-)$ & 1 & - & 1 \\
\hline \multirow[t]{2}{*}{ ANC visit (visit) } & $\geq 4$ & $225(93.8 \%)$ & $15(6.2 \%)$ & $0.1(0.016-0.645)$ & 0.015 & $0.076(0.009-0.645)^{*}$ & 0.018 \\
\hline & $<4$ & $55(83.8 \%)$ & $12(16.2 \%)$ & $0.938(0.133-6.628)$ & 1 & $0.923(0.090-9.479)$ & 1 \\
\hline \multirow[t]{2}{*}{ Anemia during $\mathrm{px}$} & Yes & $17(58.6 \%)$ & $12(41.4 \%)$ & $12.3(5.013-30.556)$ & 0.0 & $14.5(3.821-55.6)^{*}$ & 0.0 \\
\hline & No & 264 (96\%) & $14(4 \%)$ & $(-)$ & 1 & - & 1 \\
\hline \multirow[t]{2}{*}{ Drinking alcohol } & Yes & 41 (82\%) & $9(18 \%)$ & $2.9(1.231-6.958)$ & 0.015 & $6.4(1.235-33.94)^{*}$ & 0.027 \\
\hline & No & 240 (93\%) & $18(7 \%)$ & $0.000(-)$ & 1 & - & 1 \\
\hline \multirow[t]{2}{*}{ Amount of alcohol } & 3 times per week & $240(93 \%)$ & $18(7 \%)$ & $0.18(0.057-0.567)$ & 0.03 & $0.274(0.016-4.617)$ & 0.369 \\
\hline & Once a month & $29(87.8 \%)$ & $4(12.2 \%)$ & $0.369(0.060-2.274)$ & 1 & $0.274(0.016-4.617)$ & 0.369 \\
\hline
\end{tabular}

$1=$ reference category, others = Muslim, protestant

* Significantly associated with $\mathrm{P}<0.05$

chance of LBW among pregnant women with anemia was seen in Nigeria [19]. This might be because of that micronutrient deficiencies during pregnancy had been shown to have serious implications on the developing fetus. So mothers with anemia were more likely to had LBW baby.

Gestational age plays an important role in determining infants 'birth weight. Infants who are delivered prematurely $(<37$ weeks) are at higher risk to have low birth weight infants. The World Health Organization estimated about one-third of low birth weight infants is caused by prematurity. The results of the present study revealed that the chance of LBW delivery were 4.7 times higher for neonate with gestational age $<37$ weeks AOR 4.7 CI 1.08-20.44). This finding is consistent with study conducted in Jimma [15]. This finding is also consistent with the research reported from study done in Italy, Iran and Tanzania, which shows significant association of gestational age with the weight of the newborn $[21,22]$. This might be due to did not reach the optimal time which $\geq 37$ weeks of gestation and the body weight of the fetus falls due to prematurity.

One of the other factors that were found to predispose mothers to have LBW is maternal height. In this study mothers whose height $<150 \mathrm{~cm}$ was 4.6 times more likely to deliver low birth weight baby than mothers with height of $\geq 150 \mathrm{~cm}$ (AOR 4.607 CI 1.34-15.8). The reported value is consistent with the study finding in Southwestern Ethiopia and Tanzania [5, 19]. Also the study conducted in India which revealed that low birth weights were significantly higher among mothers with height $<150 \mathrm{~cm}$ [23]. This can be expected because the shorter the mother may less able to carry full term and this can lead to preterm labor and prematurity. This study also shows that mother who had >4 times ANC follow up had 92.4\% less chance to have low birth weight baby AOR 0.076 (CI 0.009-0.645) than those who have $<4$ times ANC follow. By having ANC follow up, other risk factors for LBW also be addressed like anemia, iron supplementation, counseling on danger sign of pregnancy etc. Mothers who drink alcohol during current pregnancy were 6.4 times more likely to deliver low birth weight neonate compared to mothers who didn't drink AOR 6.4 (CI 1.235-33.94).

\section{Conclusion}

The magnitude of low birth weight in this study was relatively lower than other studies. Anemia during pregnancy, height of the mother $<150 \mathrm{~cm}$, gestational age at birth $<37$ weeks, number of ANC visit and drinking alcohol were found to be significantly associated with low birth weight. 


\section{Limitation of the study}

Since this is cross-sectional study it does not show the direction of relationship. Similarly it is sensitive topic and there may be under report.

\section{Additional file}

Additional file 1. Questionnaire.

\section{Abbreviations}

LBW: low birth weight; Cl: confidence interval; AOR: adjusted odd ratio; SPSS: Statistical Package for Social Sciences; IRB: Institutional Review Board.

\section{Authors' contributions}

WA conceived and designed the study, analyzed the data. TBi and TBe: data analysis, drafting of the manuscript and advising the whole research paper. $\mathrm{TBi}$ and $\mathrm{HG}$ were involved in the interpretation of the data and contributed to manuscript preparation. HG draft the manuscript. All authors read and approved the final manuscript.

\section{Author details}

${ }^{1}$ School of Public Health, College of Health Science, Aksum University, Aksum, Ethiopia. ${ }^{2}$ School of Nursing, College of Health Science, Aksum University, Aksum, Ethiopia.

\section{Acknowledgements}

We would like to thank all study participants and data collectors for their contribution in success of our work.

\section{Competing interests}

This manuscript maintains no competing financial interests declaration from any person or Organization or non-financial competing interests such as political, personal, religious, ideological, academic, intellectual, commercial or any other.

\section{Availability of data and materials}

The data sets used and analyzed during the current study was available from the corresponding author on reasonable request.

\section{Consent to publish}

Not applicable.

\section{Ethics approval and consent to participate}

The study was reviewed and approved by the research committee of health science college of Aksum University. The objective and important of the study was explained to the study participants. Data were collected after full informed oral consent since all participants were aged above 18 years and it was approved by IRB of Aksum University. In order to keep confidentiality of the data, name was not included.

\section{Funding}

There is no funding for this research. All cost of data collection and analysis were covered by the authors.

\section{Publisher's Note}

Springer Nature remains neutral with regard to jurisdictional claims in published maps and institutional affiliations.

Received: 16 August 2018 Accepted: 27 September 2018

Published online: 01 October 2018

\section{References}

1. United Nations Children's Fund, World Health Organization. Low birth weight: country, regional and global estimates. New York: UNICEF and WHO; 2004.

2. UNSCN (United Nations System Standing Committee on Nutrition). The sixth report on the world nutrition situation: incidence of low birth weight: results from repeated national estimates (1997-2007). 2013. pp 1-128. https://www.unscn.org/files/Publications/RWNS6/report/ SCN report.pdf. ISSN: 1564-3786.

3. Alemu T, Umeta M. Prevalence and determinants of small size babies in Ethiopia: results from in-depth analyses of the Ethiopian demographic and health survey-2011. Fam Med Med Sci Res. 2015;4(3):243-50.

4. Gidey G, Hailu B, Nigus K, Hailu T, Gerensea H. Timing of first focused antenatal care booking and associated factors among pregnant mothers who attend antenatal care in Central Zone, Tigray, Ethiopia. BMC Res Notes. 2017;10(1):608

5. Kebede A, Molla B, Gerensea H. Assessment of risky sexual behavior and practice among Aksum University students, Shire Campus, Shire Town, Tigray, Ethiopia, 2017. BMC Res Notes. 2018;11:88. https://doi. org/10.1186/s13104-018-3199-7.

6. Gerensea H, Kebede A, Baraki Z, Berihu H, Zeru T, Birhane E, Hintsa S, Siyum H, Kahsay G, Gidey G, Teklay G. Consistency of integrated management of newborn and childhood illness (IMNCI) in Shire Governmental Health Institution in 2017. BMC Res Notes. 2018;11(1):476.

7. Gerensea $\mathrm{H}$, Teklay $\mathrm{H}$. Trend of hypertension morbidity and mortality in Tigray Region from 2011 to 2015, Tigray, Ethiopia. BMC Res Notes. 2018;11(1):375

8. Mariye T, Tasew H, Teklay G, Gerensea H, Daba W. Magnitude of diabetes self-care practice and associated factors among type two adult diabetic patients following at public hospitals in central zone, Tigray Region, Ethiopia, 2017. BMC Res Notes. 2018;11(1):380.

9. Seid A, Gerensea H, Tarko S, Zenebe Y, Mezemir R. Prevalence and determinants of erectile dysfunction among diabetic patients attending in hospitals of central and northwestern zone of Tigray, northern Ethiopia: a cross-sectional study. BMC Endocr Disord. 2017:17(1):16.

10. Birhane E, Kidanu K, Kassa M, Gerezgiher D, Tsegay L, Weldu B, Kidane G, Gerensea H. Lifespan and associated factors of peripheral intravenous Cannula among infants admitted in public hospitals of Mekelle City, Tigray, Ethiopia, 2016. BMC Nurs. 2017;16(1):33.

11. Baraki Z, Girmay F, Kidanu K, Gerensea H, Gezehgne D, Teklay H. A cross sectional study on nursing process implementation and associated factors among nurses working in selected hospitals of Central and Northwest zones, Tigray Region, Ethiopia. BMC Nurs. 2017;16(1):54.

12. Gerensea $\mathrm{H}$. Trend and pattern of neonatal morbidity and mortality in Tigray Region, Ethiopia. Edorium J Pediatr. 2017;6(1):1-5.

13. Girmay A, Marye T, Haftu M, Brhanu T, Gerensea H. Patients expectation strongly associated with patients perception to nursing care: hospital based cross sectional study. BMC Res Notes. 2018;11(1):310.

14. Kebede A, Gerensea H. Prevalence of needle stick injury and its associated factors among nurses working in public hospitals of Dessie town, Northeast Ethiopia, 2016. BMC Res Notes. 2018;11(1):413.

15. Gebremariam A. Factors predisposing to low birth weight in Jimma Hospital, South Western Ethiopia. East Afr Med J. 2005;82(11):554-8.

16. Maznah D, Nazar A, Oche M, Norlaili A. Risk factors for low birth weight in Nigeria: evidence from the 2013 Nigeria Demographic and Health Survey. Glob Health Action. 2013;9:12

17. Teklehaimanot N, Hailu T, Assefa H. Prevalence and factors associated with low birth weight in Axum and Laelay Maichew Districts, North Ethiopia: a comparative cross sectional study. Int J Nutr Food Sci. 2014;3(6):560566

18. Agarwal K, Agarwal A, Agrawal VK, Agrawal P, Chaudhary V. Prevalence and determinants of "low birth weight" among institutional deliveries. Ann Niger Med. 2011;5(2):48-52.

19. Assefa Nega, Berhane Yemane, Worku Alemayehu. Wealth status, mid upper arm circumference (MUAC) and antenatal care (ANC) are determinants for low birth weight in Kersa, Ethiopia. PLoS ONE. 2012;7(6):e39957.

20. Asmare G, Berhan N, Berhanu M, Alebel A. Determinants of low birth weight among neonates born in Amhara Regional State Referral Hospitals of Ethiopia: unmatched case control study. BMC Res Notes. 2018;11(1):447-51. 
21. Golestan M, Akhavan Karbasi S, Fallah R. Prevalence and risk factors for LBW in Yazd, a central city of Iran Singapore. Med J. 2011;52(10):730-73.

22. Siza JE. Risk factors associated with low birth weight of neonates among pregnant women attending a referral hospital in northern Tanzania. Tanzan J Health Res. 2008;10(1):1-8.
23. Elhassan EM, Abbaker AO, Haggaz AD, Abubaker MS, Adam I. Anaemia and low birth weight in Medani, Hospital Sudan. BMC Res Notes. 2010;3:181.

Ready to submit your research? Choose BMC and benefit from:

- fast, convenient online submission

- thorough peer review by experienced researchers in your field

- rapid publication on acceptance

- support for research data, including large and complex data types

- gold Open Access which fosters wider collaboration and increased citations

- maximum visibility for your research: over $100 \mathrm{M}$ website views per year

At BMC, research is always in progress.

Learn more biomedcentral.com/submissions 